\title{
Cranial ultrasound in preterm infants: long term follow up
}

\author{
W BAERTS AND M MERADJI
}

Departments of Paediatrics, Division of Neonatology, and Paediatric Radiology, Erasmus University and University Hospital Rotterdam and Sophia Children's Hospital, Rotterdam, the Netherlands

SUMmaRY One hundred and twenty nine high risk preterm infants (gestational ages 26-36 weeks, mean 31.2 weeks; birth weights 800-3880 g, mean $1490 \mathrm{~g}$ ) were studied by cranial ultrasound during the neonatal period, over a period of one week to three months, and at the age of 1 year. Neonatal ultrasound scanning was performed with an ATL Mk III real time echoscope, and follow up ultrasound scans at the age of 1 were performed with an Octoson static compound scanner. The neonatal scans of 66 infants were abnormal. Cerebroventricular haemorrhages were detected in 53 infants and other lesions in 19, six of whom also had haemorrhages. Posthaemorrhagic changes developed in 30 infants. The follow up scans at 1 year were abnormal in 27 children. One large parenchymal cyst was detected. All 27 scans showed ventricular dilatations; 19 were asymmetrical. About $95 \%$ of the children with normal neonatal scans and $60 \%$ with abnormal neonatal scans had normal scans at 1 year. The size and shape of the ventricular system had changed in $20 \%$ of all infants. As no major changes were seen in the ultrasound images of those studied beyond the age of 2 months cranial ultrasound follow up in high risk preterm infants should therefore be continued until the age of 2-3 months; follow up beyond that age would only rarely be necessary.

Periventricular and intraventricular haemorrhages and cerebral ischaemia are important causes of mortality and short and long term morbidity in preterm infants. The incidence of these abnormalities in infants admitted for neonatal intensive care is high, and structural cerebral defects develop in many cases. ${ }^{1-9}$ Real time ultrasound scanning is particularly useful in the detection and short term follow up of these lesions. ${ }^{10-20}$ Follow up scanning has usually been limited to the time the infant is admitted to the neonatal unit. Only few studies have indicated how long follow up should be continued to determine the full extent of neonatal haemorrhagic and ischaemic damage. ${ }^{21} 22$

Assuming that cerebral ultrasound images at the age of 1 year would reflect the end stage of any neonatal cerebral damage, we compared cranial ultrasound images at 1 year with serial neonatal images in a group of high risk preterm infants. Thus the optimal period for neonatal cranial ultrasound follow up could be determined.

\section{Subjects and methods}

We studied 129 infants. The population was com- posed of survivors from a group of high risk preterm infants who were admitted to our neonatal intensive care unit. The gestational ages ranged from 26 to 36 weeks, mean 31.2 weeks; birth weights ranged from 800 to $3880 \mathrm{~g}$, mean $1490 \mathrm{~g}$.

Neonatal scanning was conducted with an Advanced Technology Laboratories Mark III ultrasound system with a $5 \mathrm{MHz}$ scan head, producing high resolution real time images. Scanning was performed through the anterior fontanelle with the infant in his incubator or cot, as described previously. ${ }^{11} 131417$ Two sets of planes, one coronal and one parasagittal, were scanned and representative images were recorded on Polaroid film. An average of five scans was taken of each infant during the stay in the neonatal unit. Three babies were scanned once only and 21 twice only; 10 infants were scanned 10 times or more. Twelve babies were scanned only in their first week of life, but in 49 scans were taken beyond the age of 1 month.

The images were screened for haemorrhagic and cystic lesions, the size and the shape of the ventricular system were noted, and the lateral ventricular index at the intermediate part of the lateral ventricle was calculated for comparison with 
follow up scans. The follow up scans at the age of 1 were obtained with an Ausonics Octoson scanner, a highly mechanised compound water path system with up to eight $3 \mathrm{MHz}$ transducers. The resolution of this system is $1-2 \mathrm{~mm}$, resulting in high quality static images. Ultrasound scanning was performed through the temporoparietal bones with the child resting on the system's water pillow, as described previously. ${ }^{23} 24$ In several cases sedation with chloral hydrate was necessary. Two sets of planes, one semiaxial and one paracoronal, were scanned and recorded on $x$ ray film. The images were screened for cystic lesions, the size and the shape of the ventricular system was noted, and the lateral ventricular index was calculated for comparison with neonatal scans.

The ultrasound studies at the intensive care nursery were considered to be part of standard treatment, but parental consent was obtained for the studies on the infants at age 1 .

\section{Results}

Neonatal scans. The neonatal scans were normal in 63 infants and abnormal in 66. Table 1 shows findings for the 66 infants with abnormal scans. Periventricular and intraventricular haemorrhages were detected in 53 neonates. Subependymal and intraventricular haemorrhages occurred in 39 , and parenchymal haemorrhages were seen in 14. All infants whose haemorrhages could be timed bled during the first six days of life. Progression of the haemorrhages was noted in eight infants, and

Table 1 Findings in the abnormal ultrasound scans of 66 infants during the neonatal period

\begin{tabular}{|c|c|c|c|}
\hline & $\begin{array}{l}\text { Subependymal and } \\
\text { intraventricular } \\
\text { haemorrhage } \\
(n=39)\end{array}$ & $\begin{array}{l}\text { Parenchymal } \\
\text { haemorrhage } \\
(n=14)\end{array}$ & $\begin{array}{l}\text { Other lesion } \\
\text { only } \\
(n=13)\end{array}$ \\
\hline \multicolumn{4}{|l|}{ Normal ventricular } \\
\hline $\begin{array}{l}\text { Ventricular } \\
\text { dilatation }\end{array}$ & Ventricular & $12 \dagger$ & 3 \\
\hline \multicolumn{4}{|l|}{ Ventricular } \\
\hline Subependymal cyst & $8 \ddagger$ & 1 & 3 \\
\hline Porencephaly & & 9 & \\
\hline $\begin{array}{l}\text { Subependymal } \\
\text { necrosis } \\
\text { Periventricular }\end{array}$ & $3 \S$ & & 7 \\
\hline leucomalacia & $1 \|$ & & 1 \\
\hline \multicolumn{4}{|c|}{$\begin{array}{l}\text { *Ventriculoperitoneal shunt in one patient. } \\
\text { †Ventriculoperitoneal shunt in two patients. } \\
\ddagger \text { Lesion additional to and apparently unrelated to haemorrhage in two } \\
\text { patients. } \\
\text { \$Lesion additional to and apparently unrelated to haemorrhage in three } \\
\text { patients. } \\
\text { \#Lesion additional to and apparently unrelated to haemorrhage in one } \\
\text { patient. }\end{array}$} \\
\hline
\end{tabular}

posthaemorrhagic changes were seen in 30 infants. Subependymal cysts developed in seven infants and porencephaly in nine. Parenchymal cysts were present in two of the nine infants at their last neonatal scan, while porencephalic ventricular enlargements had developed in the seven others. Ventricular dilatations (lateral ventricular index $>0.35)^{25}$ occurred in 26 infants. These were asymmetrical in 10 infants; the asymmetry seemed to be the result of posthaemorrhagic porencephaly in seven, but no apparent cause was seen in the three others. Three infants had to be shunted for progressive ventricular dilatation.

Lesions, apparently unrelated to haemorrhages and probably of ischaemic origin, were seen in 19 infants. These lesions were isolated in 13 infants and were additional to haemorrhages in six. A mild ventricular dilatation was noted in three of the infants, subependymal cysts or necrosis in 14 , and cystic periventricular leucomalacia in two.

Scans at 1 year. The follow up scans taken at the age of 1 were normal in 102 children and abnormal in 27. In one child a large frontal parenchymal cyst was present. A dilated ventricular system (lateral ventricular index $>0 \cdot 35)^{26}$ was seen in all abnormal scans. Nineteen of the 27 dilatations were asymmetrical.

Neonatal versus scans at 1 year. Tables 2 and 3 summarise the neonatal findings and findings at the age of 1 . Sixty children showed no abnormality either during the neonatal period or at the age of 1 year. Forty two children with abnormal neonatal scans had normal scans at 1 year; 27 of these originally showed a subependymal and intraventricular haemorrhage, five a parenchymal haemorrhage, and 10, other abnormalities. All five parenchymal haemorrhages had been small haemorrhages.

Eighteen of the 27 abnormal scans at 1 year were the result of subependymal and intraventricular haemorrhage or parenchymal haemorrhage with

Table 2 Ultrasound findings at 1 year in 129 children related to neonatal ultrasound findings

\begin{tabular}{llll}
\hline Neonatal findings & \multicolumn{2}{l}{ Findings at 1} & year \\
\cline { 2 - 4 } & Normal & $\begin{array}{l}\text { Ventricular } \\
\text { dilatation }\end{array}$ & $\begin{array}{l}\text { Ventricular } \\
\text { asymmetry }\end{array}$ \\
\hline $\begin{array}{l}\text { Normal } \\
\begin{array}{l}\text { Subependymal and } \\
\text { intraventricular } \\
\text { haemorrhage }\end{array}\end{array}$ & 60 & 3 & 1 \\
$\begin{array}{l}\text { Parenchymal haemorrhage } \\
\begin{array}{l}\text { Other lesion } \\
\hline\end{array}\end{array}$ & 27 & 12 & 6 \\
\hline
\end{tabular}


Table 3 Ultrasound findings at 1 year in 129 children related to posthaemorrhagic changes and other lesions during neonatal period

\begin{tabular}{llll}
\hline Neonatal findings & \multicolumn{2}{l}{ Findings at 1} & year \\
\cline { 2 - 4 } & Normal & $\begin{array}{l}\text { Ventricular } \\
\text { dilatation }\end{array}$ & $\begin{array}{l}\text { Ventricular } \\
\text { asymmetry }\end{array}$ \\
\hline $\begin{array}{l}\text { Normal ventricular } \\
\text { system }\end{array}$ & 91 & 9 & 4 \\
$\begin{array}{l}\text { Ventricular } \\
\text { dilatation }\end{array}$ & 11 & 18 & 15 \\
$\begin{array}{l}\text { Ventricular } \\
\text { asymmetry }\end{array}$ & 5 & 6 & 6 \\
$\begin{array}{l}\text { Subependymal cyst } \\
\text { Porencephaly }\end{array}$ & 9 & 3 & 2 \\
$\begin{array}{l}\text { Subependymal } \\
\text { necrosis }\end{array}$ & 2 & 7 & 7 \\
$\begin{array}{c}\text { Periventricular } \\
\text { leucomalacia }\end{array}$ & 7 & 3 & 2 \\
\hline
\end{tabular}

posthaemorrhage or porencephalic ventricular dilatations, and six were the result of lesions without ventricular dilatation. The neonatal scans had been normal in the three remaining children. Neonatal ventricular dilatations had resolved, however, by the age of 1 in 11 children. Three of the 19 children with ventricular asymmetries at 1 year originally had lesions without ventricular dilatation or asymmetry. One child with ventricular asymmetry at 1 year had entirely normal neonatal scans. Asymmetries had resolved, however, at 1 year in five children. Overall, the size and the shape of the ventricular system changed in 29 of the 129 children.

Table 4 compares the neonatal scans and scans at 1 year, in relation to the period of neonatal follow up. Three of the 63 children with normal neonatal scans had abnormal scans at the age of 1 . Neonatal follow up had been limited to less than one month in all three. Differences in ventricular size and shape were found in 26 of the 66 children with abnormal neonatal scans. The changes occurred in 20 of 26 children in whom neonatal follow up had been limited to less than one month, in five of 25 who had been followed up for 1-2 months, and in one of 15 who had been followed up for over two months.

Table 4 Comparison of neonatal and 1 year scans related to period of neonatal follow up

\begin{tabular}{lll}
\hline & $\begin{array}{l}\text { Agreement } \\
\text { at 1 year }\end{array}$ & $\begin{array}{l}\text { No agreement } \\
\text { at 1 year }\end{array}$ \\
\hline All neonatal scans & 100 & 29 \\
Follow up of normal neonatal scans: & 51 & 3 \\
$<1$ month & 7 & 0 \\
$1-2$ months & 2 & 0 \\
>2 months & 6 & 20 \\
Follow up of abnormal neonatal scans: & 20 & 5 \\
1-2 month & 14 & 1 \\
$>2$ months & &
\end{tabular}

\section{Discussion}

By ultrasound scanning haemorrhagic or ischaemic cerebral lesions, or both can be shown in $35-50 \%$ of sick preterm infants admitted for neonatal intensive care. ${ }^{18} 211^{27-30}$ Most haemorrhages occur during the first week of life showing echodensities in typical localisations. Resorption of the haemorrhages occurs in the following weeks, often resulting in porencephaly at the site of the haemorrhage. Posthaemorrhagic ventricular dilatations develop in $50 \%$ of cases, being transient in about half and progressive in less than a quarter of the cases. Atrophic ventricular dilatations may develop after generalised cerebral ischaemia. Major local ischaemic lesions may be detected by the appearance of secondary haemorrhages, which sometimes occur, or by cystic changes that become visible one to three weeks later. Haemorrhages and ischaemia may coexist in several infants, resulting in changes attributable to both. Thus after some time the extent of perinatal haemorrhagic or ischaemic trauma, or both to the preterm newborn's brain will be reflected by the presence of cystic lesions of the parenchyma and the size and shape of the ventricular system. . $^{1622} 27-32$

Several studies have reported cranial ultrasound follow up in high risk preterm infants. 17192122272831 Most follow up, however, is limited to a few weeks or months while the infant is admitted to the neonatal unit. In only one study was follow up extended until the age of 1 year and in only 34 children. ${ }^{22}$ No comparison, however, was made between the neonatal scans and the findings at the age of 1 .

We compared neonatal ultrasound images and images taken at 1 year of the cerebral parenchyma and ventricular system in 129 high risk children. The agreement between neonatal findings and those at the age of 1 was best in the children with normal neonatal scans and in children with abnormal neonatal scans who were followed up for over one month while admitted to the neonatal unit. About $95 \%$ of children with normal neonatal scans had normal scans at the age of 1 . Sixty per cent of the children with abnormal neonatal scans had normal scans at 1 year. No germinal layer area lesions were seen at 1 year, probably due to the involution of this area. A large parenchymal cyst was detected in one of the two children who had cysts visible in their last neonatal scan. The parenchyma appeared to be normal at 1 year in the two children with cystic periventricular leucomalacia, but an enlarged ventricular system was seen in both.

The size and shape of the ventricles had changed in $35 \%$ of children with abnormal neonatal scans. 
Posthaemorrhagic dilatations had resolved in several infants whereas in others enlargements had appeared that had not been detected previously. Asymmetries of the ventricular system were noted in some infants in whom symmetries had been noted previously. These differences were found mainly in children in whom neonatal follow up scanning had been limited to less than one month. No major changes occurred beyond the age of 2 months in those scanned. Our findings confirm the results of a previously reported study in which in a similar group of high risk infants over $90 \%$ of all ultrasound abnormalities were detected within the first 3 months of life. ${ }^{22}$

The end stage of cerebral anatomical changes caused by perinatal insults and seen by ultrasound scanning will usually be reached by the age of 2-3 months. In conclusion, cranial ultrasound follow up in high risk preterm infants should be continued until 2-3 months to visualise the full extent of perinatal haemorrhagic or ischaemic damage, or both. Follow up beyond that age would only be necessary in a few selected cases.

\section{References}

1 Fedrick J, Butler NR. Certain causes of neonatal death II: intraventricular haemorrhage. Biol Neonate 1970;15:257-90.

${ }^{2}$ Burstein J, Papile LA, Burstein R. Intraventricular hemorrhage and hydrocephalus in premature newborns: a prospective study with CT. AJR 1979;132:631-5.

3 Albright L, Fellows R. Sequential CT scanning after neonatal intracerebral hemorrhage. AJR 1981;136:949-53.

4 Takashima S, Armstrong D, Becker LE. Old subependymal necrosis and hemorrhage in the prematurely born infants. Brain Dev 1979;4:299-304.

5 Pape KE, Armstrong D, Fitzhardinge PM. Central nervous system pathology associated with mask ventilation in the very low birthweight infant: a new etiology for intracerebellar hemorrhages. Pediatrics 1976;58:473-83.

${ }^{6}$ Shuman RM, Selednik RJ. Periventricular leucomalacia: a one-year autopsy study. Arch Neurol 1980;37:231-5.

7 Larroche JC. Post-haemorrhagic hydrocephalus in infancy: anatomical study. Biol Neonate 1972;20:287-99.

${ }^{8}$ Chaplin ER, Goldstein GW, Meyerberg DZ, Hunt JV, Tooley WH. Posthemorrhagic hydrocephalus in preterm infant. Pediatrics 1980;65:901-9.

${ }^{9}$ Hill A, Volpe JJ. Normal pressure hydrocephalus in the newborn. Pediatrics 1981;68:623-9.

10 Pape KE, Cusick G, Houang MTW, et al. Ultrasound detection of brain damage in preterm infants. Lancet 1979;i:1261-4.

11 Cooke RWI. Ultrasound examination of neonatal heads. Lancet 1979;ii:38.

12 Allan WC, Roveto CA, Sawyer LR, Courtney SE. Sector scan ultrasound imaging through the anterior fontanel. AJDC 1980;134:1028-31

13 Bejar R, Curbelo V, Coen RW, Leopold G, James H, Gluck L. Diagnosis and follow-up of intraventricular and intracerebral hemorrhage by ultrasound: studies of infant's brain through the fontanelles and sutures. Pediatrics 1980;66:661-73.
${ }^{14}$ Grant EG, Schellinger D, Borts FT, et al. Real-time sonography of the neonatal and infant head. AJNR 1980;1:487-92.

${ }^{15}$ Grant EG, Borts FT, Schellinger D, McCullough DC, Sivasubramanian KN, Smith Y. Real-time ultrasonography of neonatal intraventricular hemorrhage and comparison with computed tomography. Radiology 1981;139:687-91.

16 Johnson ML, Rumack CM, Mannes EJ, Appareti KE. Detection of neonatal intracranial hemorrhage utilizing real-time and static ultrasound. JCU 1981;9:427-33.

17 Levene MI, Wigglesworth JS, Dubowitz V. Cerebral structure and intraventricular hemorrhage in the neonate: a real-time ultrasound study. Arch Dis Child 1981;56:416-24.

${ }^{18}$ Mack LA, Wright K, Hirsch JH, et al. Intracranial hemorrhage in premature infants: accuracy of sonographic evaluation. $A J R$ 1981;137:245-50.

${ }^{19}$ Sauerbrei EE, Digney M, Harrison PB, Cooperberg PL. Ultrasonic evaluation of neonatal intracranial hemorrhage and its complications. Radiology 1981;13g:677-85.

20 Levene MI, Wigglesworth JS, Dubowitz V. Hemorrhagic periventricular leucomalacia in the neonate: a real-time ultrasound study. Pediatrics 1983;71:794-97.

${ }^{21}$ Shankaran S, Slovis TL, Bedard MP, Poland PL. Sonographic classification of intracranial hemorrhage: a prognostic indicator of mortality, morbidity, and short-term neurologic outcome. J Pediatr 1982;100:469-75.

22 Partridge JC, Babcock DS, Steichen JJ, Han BK. Optimal timing for diagnostic cranial ultrasound in low-birth-weight infants: detection of intracranial hemorrhage and ventricular dilatation. J Pediatr 1983;102:281-7.

${ }^{23}$ Kossoff G, Carpenter DA, Radovanovich G, Robinson DE, Garrett WJ. Octoson: a new rapid multi-transducer general purpose water-coupling echoscope. In: Excerpta medica international congress series No. 363. Amsterdam: Excerpta Medica, 1975:90-5.

${ }^{24}$ Haber K, Wachter RD, Christenson PC, Vaucher J, Sahn DJ, Smith JR. Ultrasonic evaluation of intracranial pathology in infants: a new technique. Radiology 1980;134:173-8.

25 Johnson ML, Dunne MG, Mack LA, Rashbaum CL. Evaluation of fetal intracranial anatomy by static and real-time ultrasound. JCU 1980;8:311-18.

${ }^{26}$ Garrett WJ, Kossoff G, Warren PS. Cerebral ventricular size in children. Radiology 1980;136:711-5.

${ }^{27}$ Levene MI, Starte DR. A longitudinal study of posthaemorrhagic ventricular dilatation in the newborn. Arch Dis Child 1981;56:905-10.

28 Allan WC, Holt PJ, Sawyer LR, Tito AM, Meade SK. Ventricular dilatation after neonatal periventricularintraventricular hemorrhage. AJDC 1982;136:589-93.

29 DeCrespigny LC, Mackay R, Murton LJ, Roy RND, Robinson HP. Timing of neonatal cerebroventricular haemorrhage with ultrasound. Arch Dis Child 1982;57:231-3.

${ }^{30}$ Morgan MEI, Cooke RWI. Timing of neonatal cerebroventricular haemorrnage with ultrasound. Arch Dis Cnila 198<;>/:811.

${ }^{31}$ Dolfin T, Skidmore MB, Fong KW, Hoskins EM, Shennan AT. Incidence, severity, and timing of subependymal and intraventricular hemorrhage in preterm infants born in a perinatal unit as detected by serial real-time ultrasound. Pediatrics 1983;71:541-6.

${ }^{32}$ Hawgood S, Spong J, Yu VUH. Intraventricular hemorrhage: incidence and outcome in a population of very-low-birth-weight infants. AJDC 1984;138:136-9.

Correspondence to Dr W Baerts, Sophia Children's Hospital, Gordelweg 160, 3038 GE Rotterdam, the Netherlands.

Received 11 February 1985 